\title{
NASA's problems in space eat into time for research
}

\begin{abstract}
Washington. The failure of the space shuttle Atlantis to complete its research agenda despite an extra day in space has raised the question of whether the US National Aeronautics and Space Administration (NASA) is asking each mission to do too much. For scientists, unexpected mechanical or maintenance problems aboard the shuttle mean less time for research.
\end{abstract}

Atlantis returned to Earth last week after an eight-day mission filled with problems. Its launch of the European Space Agency's European Retrievable Carrier, a $\$ 400$-million free-flying microgravity research platform, was delayed by 24 hours because of communications difficulties. Upon release, it was found to be incorrectly orientated and had to be moved into the correct orbit.

With the mission extended to cover this delay, the astronauts turned to their second major task - deploying the $\$ 380$-million tethered satellite system (TSS), a joint NASA-Italian Space Agency (ASI) project that involved running out a satellite from the shuttle on a $20 \mathrm{~km}$ electrically conductive tether. Researchers hoped to learn how such an apparatus functions in space and to gather data on the orbital plasma.

But, the TSS had extended only 250 metres into space when its feed mechanism jammed. After spending several hours trying to free the tether, the astronauts decided to reel the satellite back in rather than try to deploy it again. No data on the plasma were collected.

Although researchers understand the dif- ficulty of designing devices to work in a harsh and unknown environment, many believe that NASA's actions increase the chances that things will go wrong. The missions are too complex and ambitious, they say, and the emphasis on manned space flight demands more extensive safety precautions than for unmanned flight. The General Accounting Office (GAO) suggests in a recent report on space station Freedom that too little is known about the failure rates of components in space to make accurate estimates of maintenance time.

The battle over how much maintenance Freedom will require has been raging for several years. In 1989, an internal NASA study came to the surprising conclusion that crews would have to spend thousands of hours a year on extravehicular activities (EVAs) in order to keep the station in order. A 1991 redesign to save money led to a simpler station with fewer parts needing less external maintenance.

Annual external maintenance on the space station is now estimated at between 135 and 384 crew hours. But the GAO report says that the station could require many more EVAs, each one eating into the time available for research.

"From our work, we cannot prove that NASA is low on its estimations, and NASA cannot prove that it is close to the real case," says the GAO's Mona Zadjura. The GAO recommended better data on components and materials.

The most visible test of NASA's EVA

\section{Widespread CF testing inevitable, Congressional report finds}

\begin{abstract}
Washington. Despite concerns by many scientists that widespread genetic disease testing is not yet appropriate, the number of cystic fibrosis (CF) tests is expected to increase seven-fold this year, and routine $\mathrm{CF}$ carrier screening "is a matter of when, not if", a new congressional report finds. The report*, by the US Office of Technology Assessment, does not take a position as to whether (or how) such widespread testing should go ahead, but calculates that if it did, 5 million American couples might realistically be screened annually in pre-natal testing and another 125 million Americans could theoretically take part in CF carrier screening.
\end{abstract}

The issue of routine $\mathrm{CF}$ testing has been a controversial one, and a policy on the matter has embroiled the American Society of Human Genetics in months of debate.
The society's latest statement, issued earlier this year, does "not recommend" CF mutation analysis for those without a family history of the disease. An earlier statement from the society held that such testing should explicitly not be considered the "standard for care", a term with legal implication that defines that level of medical practice below which a doctor could be sued for malpractice. The OTA report says that a progression to such a care standard for CF testing could be within a year or two, but is more likely to be a gradual evolution over several years, depending on such factors as the availability of genetic counsellors and the cost of the tests, which now average a relatively expensive $\$ 170$.

Chrlstopher Anderson

* Cystic Fibrosis and DNA Tests: Implications for Carrier Screening; Office of Technology Assessment, 1992 estimates will come late in 1993 when the shuttle tries to repair the Hubble Space Telescope. Two teams, working in shifts, are expected to spend four days replacing Hubble's ill-designed optics and a number of other damaged or faulty components. Although repairing Hubble is the mission's sole task, it is not clear that the job can be done in that time. Critics point to the rescue and repair of a communications satellite by the shuttle Endeavour earlier this year, which took four times as much EVA as NASA predicted. NASA defends its projections by saying that the satellite was not designed to be recovered.

Although Hubble is not working entirely as intended, it is producing useful results and should not be written off commentators point out. Arthur Davidsen, an astrophysicist at Johns Hopkins University, finds a similar message in his experience as one of four principal investigators on the Astro 1 mission that rode in Columbia in 1990.

"Everything that was planned seemed to go wrong, but afterwards, working around the problems, we found we got a lot of science out of it", he says. "People should accept a certain amount of failure and deviation from the plan as part of learning about an unknown environment."

Most researchers concede, however, that such failures would be easier to bear if they did not have to wait so long for the next mission. The Astro project is lucky in that respect; if all goes well, it will fly again in 1994.

The Italians are hoping for a quick return into space. "With no changes or improvements in the satellite instrumentation we can go very soon, within the year", says Gianfranco Manarini, TSS programme manager for ASI. However, NASA must first find room on its busy schedule for a second try, and the problem of the jammed tether must be corrected.

lan Mundell

\section{Rifkin wins battle over NIH growth trials}

Washington. The US National Institutes of Health (NIH) has halted enrolment in a study of the effects of human growth hormone on short but otherwise normal children after pressure to stop the clinical trial from biotechnology watchdog Jeremy Rifkin and others (see Nature 358, 4; 1992). The director of NIH, Bernadine Healy, told Rifkin in a letter dated 24 July that no more children will take part in the study until an independent panel reviews the ethical questions raised in a petition sent to NIH by Rifkin's Foundation on Economic Trends and the Physicians Committee for Responsible Medicine. Rifkin believes that the hormone's potential side effects outweigh any possible benefit to the children.

Traci Watson 